\title{
SUBSTRATOS E TAMANHOS DE RECIPIENTE NA PRODUÇÃO DE MUDAS DE BARUZEIRO (Dipteryx alata Vog.)
}

\author{
Erika Katianne Costa Pinho'; Annanda Nicole Kasper Lopes²; Ana Claudia Costa ${ }^{3}$; Aline Borges Vilela Silva ${ }^{1}$; \\ Flávia Caroline Moreira Vilar; Rodrigo de Goes Esperon Reis ${ }^{3}$
}

\begin{abstract}
${ }^{1}$ Graduanda em Agronomia, Faculdade de Ciências Agrárias, Biológicas e Sociais Aplicadas, Universidade do Estado de Mato Grosso, Campus de Nova Xavantina, MT, CEP 78690-000.

Engenheira Agrônoma, Faculdade de Ciências Agrárias, Biológicas e Sociais Aplicadas, Universidade do Estado de Mato Grosso, Campus de Nova Xavantina, MT, CEP 78690-000.

${ }^{3}$ Professor, Doutor, Faculdade de Ciências Agrárias, Biológicas e Sociais Aplicadas, Universidade do Estado de Mato Grosso, Campus de Nova Xavantina, MT, CEP 78690-000

*Autor para correspondência: ekatianne121213@gmail.com
\end{abstract}

RESUMO: O baruzeiro é uma árvore frutífera disseminada no Bioma Cerrado, que apresenta vários aspectos de interesse econômico (madeira, frutos, sementes), porém, a exploração da espécie ainda é extrativista, sendo as pesquisas relacionadas à propagação fundamentais para o seu cultivo comercial. 0 presente trabalho teve como objetivo avaliar diferentes substratos e tamanhos de recipiente na produção de mudas de baruzeiro (Dipteryx alata Vog.). $O$ experimento foi conduzido no Viveiro de Mudas da Universidade do Estado de Mato Grosso - UNEMAT, no município de Nova Xavantina - MT, no período de junho a julho de 2017. O delineamento experimental utilizado foi em blocos casualizados (DBC), em esquema fatorial 3 (substratos) $\times 2$ (tamanhos de recipiente), com seis tratamentos, quatro repetições e dez plantas por parcela. Os tratamentos foram: T1 - solo + recipiente de 3,8 dm; T2 - solo + recipiente de 1,8 dm $\mathrm{dm}^{3}$, T3 - solo e esterco bovino + recipiente de 3,8 $\mathrm{dm}^{3} ;$ T4 - solo e esterco bovino + recipiente de 1,8 dm 3 ; T5 - substrato comercial + recipiente de 3,8 $\mathrm{dm}^{3} ; \mathrm{T} 6$ - substrato comercial + recipiente de $1,8 \mathrm{dm}^{3}$. De acordo com os resultados obtidos, houve diferença estatística entre os recipientes avaliados apenas para a característica altura de planta, destacando-se aquelas produzidas em recipientes menores $(1,8$ $\mathrm{dm}^{3}$ ). Com relação aos substratos, verificou-se maior crescimento das mudas nos tratamentos contendo apenas solo e substrato comercial, podendo ser utilizados na produção de mudas de baruzeiro.

PALAVRAS-CHAVE: Fabaceae, frutífera do Cerrado, planta nativa, propagação, viveiro

\section{SUBSTRATES AND SIZES OF CONTAINER IN THE PRODUCTION OF BARU (Dipteryx alata VOG.) SEEDLINGS}

\begin{abstract}
The baru is a fruit tree disseminated in all biome Cerrado, which presents several aspects of economic interest (wood, fruits, seeds), but, the exploitation of the species is still extractive, being the propagation related researchs fundamental to their commercial cultivation. The present work had to objective evaluate different substrates and containers sizes in the production of baru (Dipteryx alata Vog) seedlings. The experiment was developed in nursery seedlings in the Mato Grosso State University, in Nova Xavantina municipality, the period from june to july 2017. The experimental design utilized was of randomized blocks, in factorial 3 (substrates) $\times 2$ (containers), with six treatments, four replications and ten plants per plot. The treatments were: $T 1-$ soil + container 3,8 $\mathrm{dm}^{3} ; \mathrm{T} 2$ - soil + container 1,8 $\mathrm{dm}^{3} ; \mathrm{T} 3$ - bovine manure and soil + container 3,8 $\mathrm{dm}^{3} ; \mathrm{T} 4$ - bovine manure and soil + container 1,8 $\mathrm{dm}^{3} ; \mathrm{T} 5$ - commercial substrate + container 3,8 $\mathrm{dm}^{3} ; \mathrm{T} 6$ - commercial substrate + container $1,8 \mathrm{dm}^{3}$. According to the results obtained, there was a statistical difference between the containers evaluated only for the characteristic plant height, highlighting those produced in smaller containers $\left(1.8 \mathrm{dm}^{3}\right)$. With regard to the substrate, it was verified a greater growth of the seedlings in the treatments containing only soil and commercial substrate, being able to be used in the production of baru seedlings.
\end{abstract}

KEYWORDS: Fabaceae, fruitful of the Cerrado, native plant, propagation, nursery 


\section{INTRODUÇÃO}

O baruzeiro (Dipteryx alata Vog.) é uma espécie arbórea pertencente à família Fabaceae, disseminada no Bioma Cerrado, considerada uma das espécies mais promissoras para cultivo (Oliveira et al., 2017), devido às múltiplas possibilidades de utilizações, alta taxa de germinação de sementes e de estabelecimento de mudas.

As plantas são utilizadas para sombreamento em pastagens, recuperação de vegetação em áreas degradadas, paisagismo e sua madeira é empregada na construção civil (Martinotto et al., 2012). Dos frutos são consumidos a polpa (farinha e doces) e as sementes torradas (amêndoas) que são consideradas ricas em minerais, taninos, ácido fítico, proteínas de alta qualidade e lipídios (Siqueira et al., 2012), além disso, pode ser feita a extração de óleo (Vera et al., 2009) e produção de biodiesel (Costa et al., 2012).

A planta possui altura média de $15 \mathrm{~m}$, podendo alcançar mais de $25 \mathrm{~m}$; caule tipo tronco de cor cinza claro ou creme e apresenta placas de formato irregular descamantes; as folhas são alternadas, compostas, pinadas, pecioladas com ráquis alada, apresentando de 7 a 12 folíolos, alternos ou subopostos de coloração verde-claro na face abaxial e verde-escuro na face adaxial (Sano et al., 2016); os frutos, chamados baru, são do tipo drupa, ovoides, levemente achatados e de coloração marrom, contendo uma única semente (amêndoa) comestível (Vera et al., 2009).

A exploração da espécie ainda é extrativista, feita em sua maioria por agricultores familiares que complementam suas rendas através da comercialização da castanha e seus subprodutos (Sano et al, 2016).

Em média, uma árvore de baru demora seis anos para ter sua primeira frutificação, dependendo da qualidade do solo e da quantidade de chuvas. A safra é curta, com duração de aproximadamente três meses e geralmente ocorre uma safra produtiva a cada dois anos. Os frutos começam a ser formados em dezembro e a maturação ocorre de julho a outubro de acordo com as condições climáticas do local. Após a maturação, os frutos caem e são colhidos no chão, o que demanda tempo, pois, a dispersão dos pés é bastante irregular. No entanto, não há regularidade na comercialização do baru em razão da sazonalidade de frutificação e irregularidade das quantidades produzidas (CONAB, 2015).
Segundo Bardiviesso et al. (2011), no cultivo de uma espécie nativa, informações sobre a sua propagação são necessárias para o sucesso da produção. Atualmente existem poucas recomendações e prescrições relacionadas ao cultivo em viveiro para espécies nativas, assim como a utilização de recipientes e substratos alternativos que possam proporcionar melhor crescimento e qualidade das mudas destas espécies.

Durante a formação de mudas no viveiro pode-se destacar a importância dos recipientes e substratos adequados, que influenciam diretamente na qualidade, crescimento e no custo de produção das mudas. No entanto, ainda não há definido um sistema de cultivo para o baruzeiro, nesse sentido, estudos para desenvolver uma tecnologia de propagação são fundamentais (Ajalla et al., 2012).

O emprego de substrato e volume de recipiente adequados, utilização de ambiente protegido, irrigação e manejo correto propiciam condições para a obtenção de mudas com elevada qualidade e uniformidade de produção (Costa et al., 2015). De maneira geral, os substratos têm como principal função dar sustentação às sementes, tanto física quanto quimicamente, pois são formados por partículas minerais e orgânicas, contendo poros que podem ser ocupados por ar e água; e pela fração biológica que contém matéria orgânica (Ferreira et al., 2009). Fatores como estrutura, aeração, capacidade de retenção de água e grau de infestação de patógenos podem variar de um substrato para outro, interferindo no processo de germinação e crescimento das mudas (Moraes et al., 2007). De acordo com Wagner Júnior et al. (2006), os substratos devem apresentar vários aspectos para serem viáveis, como ausência de patógenos, fácil disponibilidade de aquisição e transporte, quantidades equilibradas de nutrientes, pH adequado, boa textura e estrutura e boa drenagem da água, garantindo que a planta receba todos os requisitos e nutrientes necessários durante 0 seu ciclo.

Oliveira et al. (2017) testando diferentes lâminas de irrigação e substratos (100\% Latossolo vermelho; $50 \%$ Latossolo vermelho e $50 \%$ areia; $45 \%$ Latossolo vermelho, $45 \%$ areia e $10 \%$ esterco bovino curtido e substrato comercial Basaplant $(\Omega)$ constataram que o substrato composto por $100 \%$ de Latossolo vermelho foi o mais indicado para a produção de mudas de baruzeiro. 
Para a produção de mudas de qualidade também é necessário o uso de recipientes adequados, assim, um dos fatores relacionados à qualidade das mudas é 0 tamanho do recipiente a ser utilizado, ou seja, o volume de substrato disponível para o bom crescimento e desenvolvimento da raiz e consequentemente da parte aérea (Zaccheu et al., 2013).

Queiroz e Melém Júnior (2001) constataram que o uso de recipientes maiores influencia diretamente o custo final da muda, pois requer maior quantidade de substrato, mão de obra durante 0 transporte às bancadas e espaço no viveiro, por outro lado, recipientes menores podem causar estresse às mudas, enovelamento do sistema radicular (Neves et al., 2005) e aumento da alocação de fotoassimilados nas raízes (Sâmor et al., 2002).

$\mathrm{Na}$ escolha de recipientes deve-se considerar o tamanho inicial e final da muda, custo de aquisição, durabilidade, facilidade de manuseio, armazenamento, transporte e a disponibilidade no mercado. De modo geral, o tamanho do recipiente deve ser escolhido de forma a proporcionar o maior volume possível de substrato às raízes, mas que apresente menor peso para facilitar o transporte. Além disso, deve-se levar em consideração que as espécies do Cerrado possuem raízes naturalmente longas, tuberosas e grossas, podendo ficar de quatro a dez vezes maiores do que a parte aérea. Nesse caso, recipientes maiores podem acondicionar melhor essas plantas, sendo mais vantajosos durante a fase inicial de crescimento destas espécies (EMBRAPA, 2016).

O objetivo do trabalho foi avaliar o crescimento de mudas de baruzeiro (Dipteryx alata Vog.) em diferentes substratos e tamanhos de recipiente em Nova Xavantina-MT.

\section{MATERIAL E MÉTODOS}

O experimento foi realizado nos meses de junho a julho de 2017 no viveiro de mudas da Universidade do Estado de Mato Grosso, Campus de Nova Xavantina, localizado a $14^{\circ} 41^{\prime} 25^{\prime \prime}$ sul e a $52^{\circ} 20^{\prime} 55^{\prime \prime}$ oeste, a uma altitude de $275 \mathrm{~m}$.

O clima da região é do tipo Aw de acordo com a classificação de Köppen, predominantemente do tipo tropical, com quatro meses de seca, de maio a agosto, precipitação anual de $1.750 \mathrm{~mm}$ e temperatura média mensal de $28^{\circ} \mathrm{C}$. A cobertura vegetal da região caracteriza-se pela ocorrência de duas zonas ecológicas, sendo o domínio dos Cerrados e das florestas de Transição da Pré-Amazônia (Marimon et al., 2010).

O solo utilizado no experimento é classificado como Tipo 3, de textura argilosa. A amostra de solo foi analisada pela Dalcin Laboratório de Análise Agropecuária, a análise química e física encontra-se descrita na Tabela 1.

Tabela 1. Análise química e física do solo utilizado como substrato na produção de mudas de baru em diferentes tamanhos de recipiente e tipos de substratos. Nova Xavantina, 2017.

\begin{tabular}{|c|c|c|c|c|c|c|c|c|c|c|c|c|c|}
\hline \multirow{2}{*}{$\begin{array}{c}\mathrm{pH} \\
\mathrm{H}_{2} \mathrm{O}\end{array}$} & \multirow{2}{*}{$\begin{array}{c}\mathrm{pH} \\
\mathrm{CaCl}_{2}\end{array}$} & $\mathrm{Ca}$ & $\mathrm{Mg}$ & K & $\mathrm{Al}+\mathrm{H}$ & Al & $\mathrm{Ca}+\mathrm{Mg}$ & $\mathrm{P}$ & $\mathrm{Zn}$ & $\mathrm{Cu}$ & $\mathrm{Mn}$ & $\mathrm{Fe}$ & B \\
\hline & & \multicolumn{6}{|c|}{ 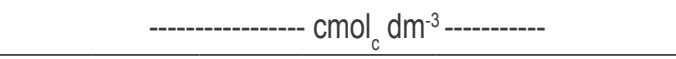 } & \multicolumn{6}{|c|}{------------ mg dm³ } \\
\hline 5,4 & 4,2 & 0,16 & 0,16 & 0,03 & 3,20 & 0,38 & 0,32 & 0,6 & 0,18 & 0,52 & 2,67 & 11,31 & 0,233 \\
\hline \multicolumn{2}{|c|}{$\mathrm{V}(\%)$} & \multicolumn{2}{|c|}{ MO } & \multicolumn{2}{|c|}{ Areia } & \multicolumn{2}{|c|}{ Silte } & \multicolumn{2}{|c|}{ Argila } & \multicolumn{2}{|c|}{ СTC } & \multicolumn{2}{|c|}{ SB } \\
\hline & & \multicolumn{6}{|c|}{ 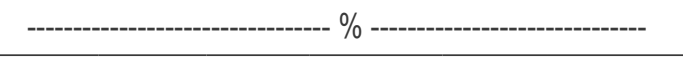 } & & & \multicolumn{4}{|c|}{-cmol $\mathrm{dm}^{-3}$} \\
\hline \multicolumn{2}{|c|}{9,9} & \multicolumn{2}{|c|}{1,13} & \multicolumn{2}{|c|}{48} & \multicolumn{2}{|r|}{5} & \multicolumn{2}{|c|}{47} & \multicolumn{2}{|c|}{3,5} & \multicolumn{2}{|c|}{0,3} \\
\hline
\end{tabular}

pH - potencial hidrogeniônico; $\mathrm{Ca}$ - cálcio; $\mathrm{Mg}$ - magnésio; $\mathrm{K}$ - potássio; $\mathrm{Al}$ - alumínio; $\mathrm{H}$ - hidrogênio; $\mathrm{P}$ - fósforo; Zn - zinco; Cu - cobre; Mn - manganês; Fe- ferro; B- boro; V\% - saturação por bases, em \%; MO- matéria orgânica; CTC - capacidade de troca de cátions; SB - soma de bases.

As sementes de baru (Dipteryx alata Vog.), Fabaceae, utilizadas no experimento foram doadas pelo Laboratório de Qualidade de Sementes da Universidade do Estado de Mato Grosso, e selecionadas as de melhor aspecto físico, sem injúrias e que não se apresentavam chochas. A semeadura foi realizada manualmente, em sacos plásticos de polietileno nas dimensões de $15 \times 25$ $\mathrm{cm}\left(1,8 \mathrm{dm}^{3}\right)$ e $20 \times 30 \mathrm{~cm}\left(3,8 \mathrm{dm}^{3}\right)$, semeando-se 3 sementes por saco, a aproximadamente $2 \mathrm{~cm}$ 
de profundidade, totalizando 720 sementes. Após o enchimento dos sacos plásticos, estes foram dispostos em bancadas de plástico no Viveiro de Produção de Mudas da UNEMAT, com telado de 50 $\%$ de sombreamento.

Após 18 dias do plantio foi realizado 0 desbaste das mudas, mantendo-se apenas a planta mais vigorosa por recipiente. A irrigação foi realizada diariamente com regador distribuindo-se a água uniformemente entre as mudas. 0 controle de plantas daninhas foi realizado manualmente eliminando-se as plantas logo após a emergência.

Como substratos foram utilizados solo, solo + esterco bovino curtido na proporção 2:1 e substrato comercial (Bioflora $囚$ ) que apresenta como matérias primas: casca de pinus/eucalipto, serragem de madeira, carvão vegetal, rocha calcárea, superfosfato simples, nitrato de amônio e casca de arroz. As características físicas e químicas do substrato comercial encontram-se descritas na Tabela 2.

Tabela 2. Características físicas e químicas do substrato Bioflora®, utilizado na produção de mudas de baru (Dipetyx alata Vog.). Nova Xavantina, 2017.

\begin{tabular}{ccccccc}
\hline \multirow{2}{*}{ Diluição 1:5 } & \multirow{2}{*}{ Umidade Máxima } & \multicolumn{2}{c}{ Densidade } & \multicolumn{2}{c}{ Aditivos \% } & \multirow{2}{*}{ CRA } \\
\cline { 3 - 6 } & & & (base seca) & \multicolumn{2}{c}{$(\mathrm{m} / \mathrm{m}$, base seca) } & \\
\hline $\mathrm{CE}(\mathrm{mS} / \mathrm{cm})$ & $\mathrm{pH}$ & $\%(\mathrm{~m} / \mathrm{m})$ & $\mathrm{kg} / \mathrm{m}^{3}$ & Fertilizante & Corretivo & $\%(\mathrm{~m} / \mathrm{m})$ \\
\hline $0,70 \mathrm{a}+/-0,3$ & $6,00+/-0,5$ & 60 & 380 & 0,3 a 0,9 & 0,6 a 0,9 & 150 \\
\hline
\end{tabular}

CE: condutividade elétrica; pH: pontecial hidrogeniônico; CRA: capacidade de retenção de água.

0 delineamento experimental adotado foi em Blocos Casualizados (DBC) em esquema fatorial (3 substratos $\times 2$ tamanhos de recipiente), com seis tratamentos, quatro repetições e dez plantas por parcela, totalizando 240 mudas.

Os tratamentos foram T1 - solo + recipiente de 3,8 dm³ ;2- solo + recipiente de 1,8 $\mathrm{dm}^{3} ;$ T3- solo e esterco bovino + recipiente de $3,8 \mathrm{dm}^{3}$; T4- solo e esterco bovino + recipiente de 1,8 $\mathrm{dm}^{3}$; T5- substrato comercial + recipiente de $3,8 \mathrm{dm}^{3}$; T6- substrato comercial + recipiente de $1,8 \mathrm{dm}^{3}$.

Após 60 dias da semeadura foram avaliadas as seguintes variáveis agronômicas: altura de plantas $(\mathrm{cm})$, mensurada com o auxílio de uma régua milimetrada, medindo-se a distância entre o colo da planta e a gema apical; diâmetro do caule (mm), com o auxílio de um paquímetro digital, medindo-se a espessura do caule $2 \mathrm{~cm}$ acima do colo; número de folhas e folíolos; massa fresca e seca da parte área e da raiz e Índice de Qualidade de Dickson.

Ao final do experimento as mudas foram retiradas dos saquinhos, lavadas em água corrente $\mathrm{e}$ a raiz foi separada da parte aérea com auxílio de uma tesoura de poda. Após este procedimento, a parte aérea e o sistema radicular foram colocados em sacos de papel e pesados separadamente em balança analítica para determinação da massa fresca, subtraindo-se 0 peso do saquinho. Posteriormente, o material foi levado à estufa com circulação forçada de ar à temperatura de $65{ }^{\circ} \mathrm{C}$, no Laboratório de Solos da Universidade do Estado de Mato Grosso, Campus de Nova Xavantina, até atingir peso constante, sendo em seguida pesados para se determinar a massa seca das partes.

O Índice de Qualidade de Dickson foi obtido conforme Costa et al. (2011) aplicando-se a fórmula:

Onde:

MST: Massa seca total (g) (MSPA+MSR); ALT: Altura (cm); DC: Diâmetro do caule (mm); MSPA: Massa seca da parte aérea (g); MSR: Massa seca de raízes $(\mathrm{g})$.

Os dados foram submetidos à análise de variância, sendo as médias comparadas pelo teste Tukey, ao nível de $5 \%$ de probabilidade, utilizando-se 0 software Sisvar (Ferreira, 2014).

\section{RESULTADOS E DISCUSSÃO}

De acordo com os resultados da análise de variância, verificou-se que houve interação significativa entre os fatores testados (tamanho de recipiente $\mathrm{x}$ substrato), apenas para o número de folhas (Tabela 3), verificando-se as médias de 3,30; 2,43 e 3,89 folhas para as plantas produzidas nos substratos contendo, respectivamente, solo, solo+esterco bovino e substrato comercial no recipiente de 1,8 L; e as médias de 
3,$91 ; 2,15$ e 3,77 folhas para as mudas produzidas nos substratos contendo, respectivamente, solo, solo+esterco bovino e substrato comercial no recipiente de 3,8 L (Tabela 6).

Tabela 3. Análise de variância para as características altura de planta, diâmetro do caule, número de folhas (NF), número de folíolos (NFO), massa fresca da parte aérea (MFPA) e das raízes (MFRA), massa seca da parte aérea (MSPA) e das raízes (MSRA) e índice de qualidade de Dickson (IQD) de mudas de baru produzidas em diferentes substratos e tamanhos de recipiente. Nova Xavantina, 2017.

\begin{tabular}{ccccccccccc}
\hline Fontes de variação & GL & Altura $(\mathrm{cm})$ & Diâmetro $(\mathrm{mm})$ & NF & NFO & MFPA $(\mathrm{g})$ & MFRA $(\mathrm{g})$ & MSPA $(\mathrm{g})$ & MSRA $(\mathrm{g})$ & IQD \\
\hline Substrato & 2 & $9,869^{* *}$ & $0,468^{*}$ & $5,537^{* *}$ & $153,925^{* *}$ & $9,314^{* *}$ & $0,845^{\text {ns }}$ & $1,394^{* *}$ & $0,064^{*}$ & $0,036^{* *}$ \\
Recipiente & 1 & $2,593^{* *}$ & $0,345^{\text {ns }}$ & $0,033^{\text {ns }}$ & $0,002^{\text {ns }}$ & $0,166^{\text {ns }}$ & $0,182^{\text {ns }}$ & $0,033^{\text {ns }}$ & $0,022^{\text {ns }}$ & $0,010^{\text {ns }}$ \\
S x R & 2 & $1,261^{\text {ns }}$ & $0,070^{\text {ns }}$ & $0,450^{*}$ & $4,202^{\text {ns }}$ & $0,006^{\text {ns }}$ & $0,066^{\text {ns }}$ & $0,000^{\text {ns }}$ & $0,000^{\text {ns }}$ & $0,002^{\text {ns }}$ \\
Bloco & 3 & $0,578^{\text {ns }}$ & $0,13^{\text {ns }}$ & $0,127^{\text {ns }}$ & $8,672^{\text {ns }}$ & $0,08^{\text {ns }}$ & $0,294^{\text {ns }}$ & $0,021^{\text {ns }}$ & $0,032^{\text {ns }}$ & $0,008^{\text {ns }}$ \\
Erro & 15 & 0,389 & 0,11 & 0,109 & 2,96 & 0,116 & 0,319 & 0,008 & 0,014 & 0,004 \\
CV $(\%)$ & & 8,11 & 9,91 & 10,21 & 7,15 & 12,38 & 21,86 & 9,78 & 20,47 & 17,67 \\
\hline
\end{tabular}

ns -não significativo, ${ }^{*}$-significativo a $5 \%$ de probabilidade, ${ }^{* *}$-significativo a $1 \%$ de probabilidade. GL - grau de liberdade.

Para as variáveis altura de plantas, diâmetro do caule, número de folíolos, massa fresca da parte aérea, massa seca da parte aérea e da raiz e índice de qualidade de Dickson, houve efeito apenas dos substratos testados. Com relação aos tamanhos dos recipientes, houve diferença estatística apenas para a altura de plantas $(7,68 \mathrm{~cm})$.

Verifica-se na Tabela 4 que os substratos contendo solo e substrato comercial proporcionaram maior altura de plantas, diâmetro do caule, número de folíolos, massa fresca e seca da parte aérea.

Tabela 4. Médias da altura de planta $(H)$, diâmetro do caule (D), número de folíolos (NFO), massa fresca da parte aérea (MFPA) e das raízes (MFRA), massa seca da parte aérea (MSPA) e das raízes (MSRA) e índice de qualidade de Dickson (IQD) de mudas de baruzeiro produzidas em diferentes substratos e tamanhos de recipiente. Nova Xavantina, 2017.

\begin{tabular}{ccccccccc}
\hline Substratos & $\mathrm{H}(\mathrm{cm})$ & $\mathrm{D}(\mathrm{mm})$ & NFO & MFPA $(\mathrm{g})$ & MFRA $(\mathrm{g})$ & MSPA $(\mathrm{g})$ & MSRA $(\mathrm{g})$ & IQD \\
\hline Solo & $8,32 \mathrm{a}$ & $3,67 \mathrm{a}$ & $25,83 \mathrm{a}$ & $3,20 \mathrm{a}$ & $2,63 \mathrm{a}$ & $1,20 \mathrm{a}$ & $0,69 \mathrm{a}$ & $0,47 \mathrm{a}$ \\
\hline Solo+esterco & $6,40 \mathrm{~b}$ & $3,21 \mathrm{~b}$ & $19,09 \mathrm{~b}$ & $1,52 \mathrm{~b}$ & $2,23 \mathrm{a}$ & $0,45 \mathrm{~b}$ & $0,54 \mathrm{a}$ & $0,34 \mathrm{~b}$ \\
\hline Substrato & $8,34 \mathrm{a}$ & $3,58 \mathrm{ab}$ & $27,32 \mathrm{a}$ & $3,53 \mathrm{a}$ & $2,88 \mathrm{a}$ & $1,14 \mathrm{a}$ & $0,54 \mathrm{a}$ & $0,37 \mathrm{~b}$ \\
\hline
\end{tabular}

Médias seguidas pela mesma letra na coluna não diferem entre si pelo teste de Tukey a $5 \%$ de probabilidade.

Oliveira et al. (2014) observaram que mudas de baruzeiro produzidas em substratos com maiores porcentagens de esterco bovino na mistura com solo, apresentaram maior altura e número de folhas, porém, verificaram maior mortalidade de plantas no substrato que continha $80 \%$ de esterco em comparação ao substrato com $20 \%$, já que as mudas produzidas no primeiro não apresentaram desenvolvimento radicular adequado. As inúmeras espécies de plantas nativas que ocorrem no bioma Cerrado, como o baruzeiro, são resistentes ou tolerantes às condições edáficas consideradas desfavoráveis às plantas cultivadas.
Canesin e Corrêa (2006) não observaram diferenças significativas em relação ao crescimento inicial de mudas de mamoeiro quando comparados a substratos contendo esterco bovino, fertilizante mineral (P e K) e esterco bovino associado a fertilizante mineral $(\mathrm{P}$ e K), apesar dos maiores teores de fósforo terem sido encontrados na massa seca das mudas cultivadas com esterco.

Costa et al. (2012) também verificaram menor massa do sistema radicular das mudas de baruzeiro produzidas em substrato com elevada porcentagem 
(100\%) de esterco bovino, característica essa também observada por Paiva Sobrinho et al. (2010) estudando diferentes substratos em mudas de baruzeiro, cagaiteira e mangabeira na mistura de solo, esterco e casca de arroz carbonizada.

Oliveira et al. (2014) trabalhando com a produção de mudas de camu-camu (Myrciaria dubia), frutífera silvestre encontrada em áreas de várzea da Amazônia, em diferentes substratos, observaram maior crescimento em altura de plantas em substrato comercial, por este material apresentar melhores características de retenção de água, aeração e teores de nutrientes, corroborando com os resultados do presente trabalho onde observou-se maior altura $(8,34 \mathrm{~cm})$ nas mudas produzidas em substrato comercial, embora não tenha diferido estatisticamente do substrato composto apenas por solo.

Ajalla et al. (2012) avaliando mudas de baru sob três níveis de sombreamento e quatro classes texturais de solo, constataram que solos de textura argilosa propiciaram maior crescimento em todo o ciclo, seguido das texturas média e arenosa, o que corrobora com os resultados obtidos neste trabalho em que 0 substrato contendo apenas solo de textura argilosa (Tabela 1) favoreceu os parâmetros de crescimento avaliados (Tabela 4).

Com relação ao Índice de qualidade de Dickson (IQD), verificou-se maior valor para esta característica no substrato contendo apenas solo $(0,47)$, e menor valor no substrato solo + esterco bovino $(0,34)$, que não diferiu estatisticamente do substrato comercial $(0,37)$. Fonseca et al. (2002) consideram o IQD um bom indicador da qualidade das mudas, haja vista que em seu cálculo são considerados a robustez e o equilíbrio da distribuição da biomassa na muda, ponderando os resultados de vários parâmetros importantes empregados para avaliação da qualidade.

A Tabela 5 indica que as mudas produzidas nos recipientes menores $\left(1,8 \mathrm{dm}^{3}\right)$ apresentaram maior altura (Figura 1). Para as demais características avaliadas no trabalho, não houve diferenças entre os tamanhos de recipientes utilizados.

Tabelas 5. Médias da altura de planta $(H)$, diâmetro do caule (D), número de folíolos (NFO), massa fresca da parte aérea (MFPA) e das raízes (MFRA), massa seca da parte aérea (MSPA) e das raízes (MSRA) e índice de qualidade de Dickson (IQD) de mudas de baru produzidas em diferentes substratos e tamanhos de recipiente. Nova Xavantina, 2017.

\begin{tabular}{ccccccccc}
\hline Tamanhos de recipiente & $\mathrm{H}(\mathrm{cm})$ & $\mathrm{D}(\mathrm{mm})$ & NFO & MFPA $(\mathrm{g})$ & MFRA $(\mathrm{g})$ & MSPA $(\mathrm{g})$ & MSRA $(\mathrm{g})$ & IQD \\
\hline Recipiente 1,8 $\mathrm{dm}^{3}$ & $8,02 \mathrm{a}$ & $3,61 \mathrm{a}$ & $24,07 \mathrm{a}$ & $2,83 \mathrm{a}$ & $2,67 \mathrm{a}$ & $0,97 \mathrm{a}$ & $0,62 \mathrm{a}$ & $0,42 \mathrm{a}$ \\
\hline Recipiente $3,8 \mathrm{dm}^{3}$ & $7,36 \mathrm{~b}$ & $3,37 \mathrm{a}$ & $24,09 \mathrm{a}$ & $2,67 \mathrm{a}$ & $2,49 \mathrm{a}$ & $0,90 \mathrm{a}$ & $0,56 \mathrm{a}$ & $0,37 \mathrm{a}$ \\
\hline
\end{tabular}

Médias seguidas pela mesma letra na coluna não diferem entre si pelo teste de Tukey a $5 \%$ de probabilidade.

As mudas produzidas em recipientes menores $\left(1,8 \mathrm{dm}^{3}\right)$, devido a menor circunferência do saquinho, ficaram em uma condição mais adensada sobre a bancada em relação as mudas produzidas em recipientes de maior dimensão, o que pode ter causado maior competição por luz, proporcionando maior crescimento em altura.

Em contraste, Danner et al. (2007) estudando a formação de mudas de jabuticabeira (Plinia sp.) em diferentes substratos e recipientes, observaram que as mudas que se desenvolveram no recipiente maior $(1,96$ $\mathrm{dm}^{3}$ ) apresentaram maior acúmulo de massa seca da parte aérea e maior área foliar, independentemente do substrato utilizado, quando comparado com as mudas desenvolvidas no recipiente menor $\left(0,57 \mathrm{dm}^{3}\right)$. Recipientes de maior volume geralmente proporcionam melhor crescimento do sistema radicular das mudas, todavia influenciam diretamente em seu custo de produção final, pois resulta em maior volume de substrato a ser utilizado, maior espaço de ocupação no viveiro e maior quantidade de mão de obra utilizada no transporte das mudas, além de aumento dos insumos (Queiroz e Melém Junior, 2001).

Para o número de folhas, como houve interação significativa entre os fatores avaliados, foi realizado 0 desdobramento da interação. Verifica-se na Tabela 6, que independentemente do tamanho do recipiente, a utilização de solo ou substrato comercial proporcionou maior incremento no número de folhas. No entanto, para substrato solo, sugere-se utilizar recipiente de maior dimensão (3,8 $\mathrm{dm}^{3}$ ) por proporcionar maior número de folhas. 
Tabela 6. Médias do número de folhas de mudas de baru produzidas em diferentes substratos e tamanhos de recipiente. Nova Xavantina, 2017.

\begin{tabular}{ccc}
\hline Substrato/ Recipiente & Recipiente $1,8 \mathrm{dm}^{3}$ & Recipiente 3,8 $\mathrm{dm}^{3}$ \\
\hline Solo & $3,30 \mathrm{a} \mathrm{B}$ & $3,91 \mathrm{a} \mathrm{A}$ \\
Solo+esterco & $2,43 \mathrm{~b} \mathrm{~A}$ & $2,15 \mathrm{~b} \mathrm{~A}$ \\
Substrato & $3,89 \mathrm{a} \mathrm{A}$ & $3,77 \mathrm{a} \mathrm{A}$ \\
\hline
\end{tabular}

Médias seguidas pela mesma letra minúscula na coluna e maiúscula na linha não diferem entre si pelo teste de Tukey a $5 \%$ de probabilidade.

Na produção de mudas de jatobá (Hymenaea courbaril) sob diferentes substratos (terra de subsolo, areia lavada, esterco bovino e resíduo industrial de caulim) e volumes de recipiente (saco de polietileno preto de $0,36 \mathrm{dm}^{3}, 1,09 \mathrm{dm}^{3}$ e 1,66 dm $\mathrm{dm}^{3}$, constatouse que o recipiente de $1,66 \mathrm{dm}^{3}$ e a composição do substrato na proporção de $40 \%$ terra de subsolo e $60 \%$ caulim, proporcionaram maior número de folhas (Oliveira et al., 2014). Silva et al. (2010) testando diferentes substratos e recipientes na propagação do maracujazeiro amarelo observaram que os substratos Plantmax e solo + esterco bovino na proporção 2:1 nos sacos plásticos de $10,7 \mathrm{dm}^{3}$ proporcionaram maior altura, número de folhas e massa seca da parte aérea.

Verifica-se na Figura 1 a superioridade das mudas de baru produzidas em substratos contendo solo (T1 e T2) e substrato comercial (T5 e T6), em detrimento ao substrato composto por solo + esterco bovino (T3 e T4). De maneira geral, estes dois substratos podem ser recomendados para a produção de mudas de baru, no entanto, em função do elevado custo do substrato comercial, sugere-se a utilização de solo como substrato por possivelmente ser a alternativa mais viável economicamente.

Os substratos contendo apenas solo ou substrato comercial favoreceram os atributos de crescimento avaliados na produção de mudas de baru. 0 crescimento de mudas não foi influenciado pelo tamanho de recipiente utilizado na produção de mudas de baru, com exceção da altura que foi favorecida nos recipientes de $1,8 \mathrm{dm}^{3}$.

Figura 1. Mudas de baru produzidas em diferentes substratos e tamanhos de recipiente. Nova Xavantina, 2017.

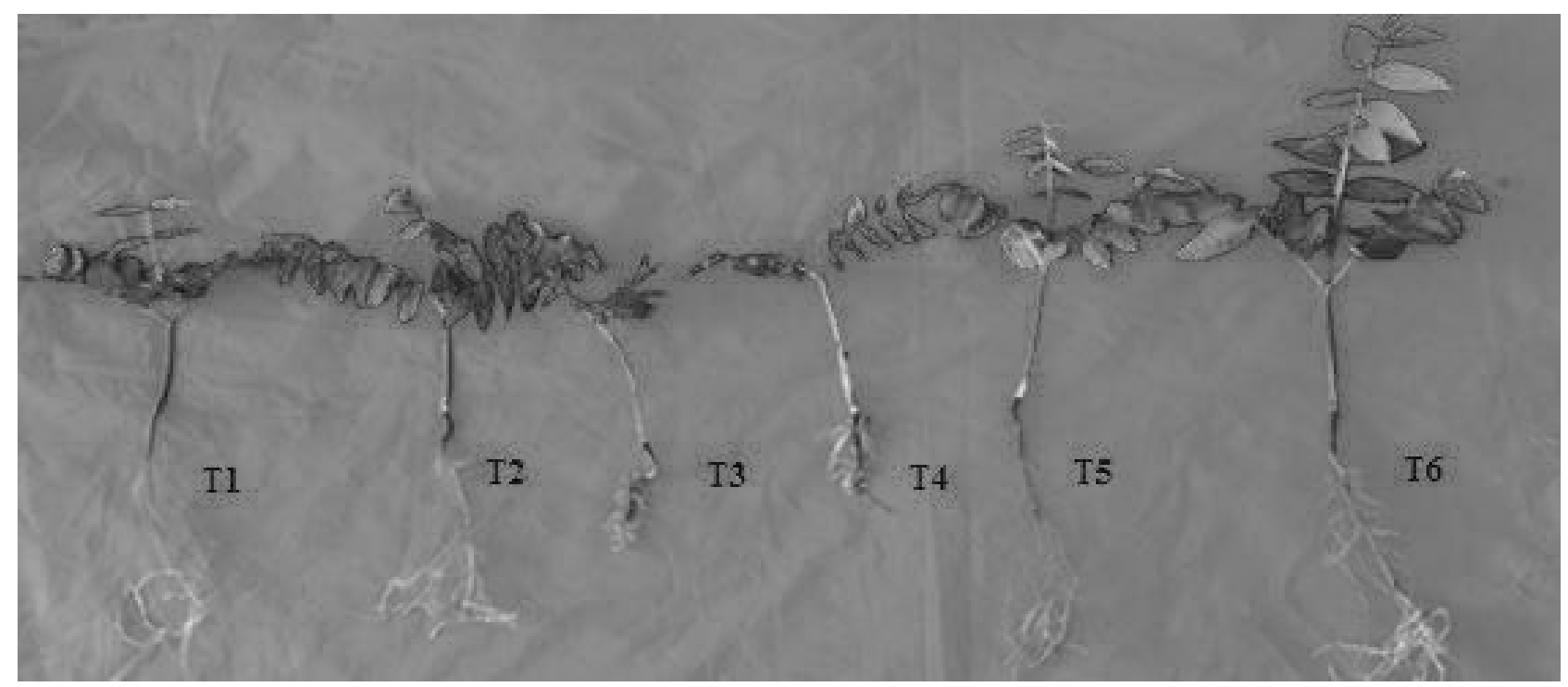

T1 (Solo + recipiente 3,8 $\left.\mathrm{dm}^{3}\right)$, T2 (Solo + recipiente 1,8 $\left.\mathrm{dm}^{3}\right)$, T3 (Solo + esterco bovino + recipiente 3,8 dm ${ }^{3}$ ), T4 (Solo + esterco bovino + recipiente 1,8 dm $\mathrm{dm}^{3}$, T5 (Substrato comercial + recipiente 3,8 dm ${ }^{3}$ ) e T6 (Substrato comercial + recipiente $\left.1,8 \mathrm{dm}^{3}\right)$. 


\section{REFERÊNCIAS BIBLIOGRÁFICAS}

Ajalla, A.C.A.; Volpe, E.; Vieira, M.C.; Zárate, N.A.H. Produção de mudas de baru (Dipteryx alata Vog.) sob três níveis de sombreamento e quatro classes texturais de solo. Revista Brasileira de Fruticultura, 2012, 34, 888-896.

Bardiviesso, D.M.; Maruyama, W.I.; Reis, L.L.; Modesto, J.H.; Rezende, W.E. Diferentes substratos e recipientes na produção de mudas de guabiroba (Campomanesia pubescens O. Berg). Revista Científica Eletrônica de Agronomia, 2011, 18, 52-59.

Canesin, R.C.F.S.; Corrêa, L.S. Uso de esterco associado à adubação mineral na produção de mudas de mamoeiro (Carica papaya L.). Revista Brasileira de Fruticultura, 2006, 28, 481-486.

CONAB-Companhia Nacional de Abastecimento. Baru (amêndoa).2015.Disponívelem:<http://www.conab.gov. br/OlalaCMS/uploads/arquivos/15_10_16_16_49_44_ conjuntura_baru_setembro_2015.pdf>. Acesso em 20 out. 2017.

Costa, E.; Dias, J.G.; Lopes, K. G.; Binotti, F.F.S.; Cardoso, E.D. Telas de sombreamento e substratos na produção de mudas de Dipteryx alata Vog. Floresta e Ambiente, 2015, 22, 416-425.

Costa, E.; Oliveira, L.C.; Espírito Santo, T.L.; Leal, P.A.M. Production of baruzeiro seedling in different protected environments and substrates. Engenharia Agrícola, 2012, 32, 633-641.

Costa, E.; Leal, P.A.M.; Rego, N.H.; Benatti, J. Desenvolvimento inicial de mudas de jatobazeiro do cerrado em Aquidauana - MS. Revista Brasileira de Fruticultura, 2011, 33, 215-226.

Danner, M.A.; Citadin, I.; Fernandes Junior, A.A.; Assmann, A.P.; Mazaro, S.M.; Sasso, S.A.Z. Formação de mudas de jabuticabeira (Plinia sp.) em diferentes substratos e tamanhos de recipientes. Revista Brasileira de Fruticultura, 2007, 20, 179-182.

EMBRAPA-Empresa Brasileira de Pesquisa e Agropecuária. Manual de viveiro e produção de mudas: espécies arbóreas nativas do Cerrado. Brasília, 2016.
Disponível em: <https://ainfo.cnptia.embrapa.br/digital/ bitstream/item/141891/1/Manual-de-Viveiro-e-pro ducao-de-mudas.pdf>. Acesso em 22 out. 2017.

Ferreira, D.F. Sisvar: a Guide for its Bootstrap procedures in multiple comparisons. Ciência e Agrotecnologia, 2014, 38, 109-112.

Ferreira, M.G.R.; Rocha, R.B.; Gonçalves, E.P.; Alves, E.U; Ribeiro. G.D. Influência do substrato no crescimento de mudas de cupuaçu (Theobroma grandiflorum Schum.). Acta Scientiarum Agronomy, 2009, 31, 677-681.

Fonseca, E.P.; Valéri, S.V.; Miglioranza, E.; Fonseca, N.A.N.; Couto, L. Padrão de qualidade de mudas de Trema micrantha (L.) Blume, produzidas sob diferentes períodos de sombreamento. Revista Árvore, 2002, 26, 515-523.

Marimon, B.S.; Felfili, J.M.; Lima, E.S.; Duarte, W.M.G.; Marimon-Júnior, B.H. Environmental determinants for natural regeneration of gallery forest at the Cerrado/ Amazonia boundaries in Brazil. Acta Amazônica, 2010, 40, 107- 118.

Martinotto, F.; Martinotto, C.; Coelho, M.F.B.; Azevedo, R.A.B.; Albuquerque, M.C.F. Sobrevivência e crescimento inicial de espécies arbóreas nativas do Cerrado em consórcio com mandioca. Pesquisa Agropecuária Brasileira, 2012, 47, 22- 29.

Moraes, L.A.C.; Garcia, T.B.; Sousa, N.R.; Moreira, A. Indução de brotação apical em mudas provenientes de sementes e do enraizamento de estacas de mangostãozeiro. Acta Scientiarum Agronomy, 2007, 29, 665-669.

Neves, C.S.V.J.; Medina, C.C.; Azevedo, M.C.B.; Higa, A.R.; Simon, A. Efeitos de substratos e recipientes utilizados na produção de mudas sobre a arquitetura do sistema radicular de árvores de acácia negra. Revista Árvore, 2005, 29, 897-905.

Oliveira, H.F.E.; Souza, C.L.; Félix, D.V.; Fernandes, L.S.; Xavier, P.S.; Alves, L.M. Desenvolvimento inicial de mudas de baruzeiro (Dipteryx alata Vog) em função de substratos e lâminas de irrigação. Irriga, 2017, 22 , 288-300. 
Oliveira, L.S.B.; Andrade, L.A.; Alves, A.S.; Gonçalves, G.S. Substrato e volume de recipiente na produção de mudas de jatobá (Hymenaea courbaril L.). Nativa, 2014, 02, 103-107.

Oliveira, L.C.; Costa, E.; Sobrinho, M.F.O.; Binotti, F.F.S.; Maruyama, W.I.; Alves, A.C. Esterco bovino e fibra de coco na formação de mudas de baruzeiro. Revista de Agricultura Neotropical, 2014, 1, 42-51.

Oliveira, A.E.Z.; Tavares, D.V.L.; Souza, L.C.D.; Barros, W.S. Avaliação de substratos para produção de mudas camu camu (Myrciaria dúbia)emsacolas plásticas. 2014. Disponível em: <http://www.aems.edu.br/conexao/ edicaoanterior/Sumario/2014/downloads/2014/ Avalia $\%$ C3\%A7\%C3\%A30\%20de\%20substratos $\% 20$ para $\% 20$ produ $\%$ C $3 \%$ A $7 \%$ C $3 \%$ A 30 $\% 20$ de $\% 20$ mudas $\% 20$ camu $\% 20$ camu $\% 20$ (Myrciaria $\% 20$ d\%C3\%BAbia)\%20em\%20sacolas\%20pl\%C3\%A1sticas.pdf>. Acesso em 13 set. 2017.

Paiva Sobrinho, S; Luz, P.B.; Silveira, T.L.S.; Ramos, D.T.; Neves, L.G.; Barelli, M.A.A. Substratos na produção de mudas de três espécies arbóreas do cerrado. Revista Brasileira de Ciências Agrárias, 2010, 5, 238-243.

Queiroz, J.A.; Melém Júnior, N.J. Efeito do tamanho do recipiente sobre o desenvolvimento de mudas de açaí (Euterpe olaracea Mart.). Revista Brasileira de Fruticultura, 2001, 21, 460-462.

Samôr, O.J.M.; Carneiro, J.G.A.; Barroso, D.G.; Leles, P.S.S. Qualidade de mudas de angico e sesbânia, produzidas em diferentes recipientes e substratos. Revista Árvore, 2002, 26, 209-215.
Sano, S.M.; Brito, M.A; Ribeiro, J.F. Baru (Dipteryx alata). In: Plantas Para o Futuro - região Centro-oeste. Brasilia: MMA, 2016. 203-215.

Silva, E.A.; Maruyama, W.I.; Mendonça, V.; Francisco, M.G.S.; Bardiviesso, D.M.; Tosta, M.S. Composição de substratos e tamanho de recipientes na produção e qualidade das mudas de maracujazeiro 'amarelo'. Ciência e Agrotecnologia, 2010, 34, 588-595.

Siqueira, E.M.A.; Marin, A.M.F.; Cunha, M.S.B.; Fustinoni, A.M.; Lívia Santıana, P.; Arruda, S.F. Consumption of baru seeds [Dipteryx alata Vog.], a Brazilian savanna nut, prevents iron-induced oxidative stress in rats. Food Research International, 2012, 45, 427-433.

Vera, R.; Soares-Júnior, M.S.; Naves, R.V.; Souza. E.B.; Fernandes, E.P.; Caliari, M.; Leandro, W.M. Características de amêndoas de barueiros (Dipteryx alata Vog.) de ocorrência natural no Cerrado do Estado de Goiás, Brasil. Revista Brasileira de Fruticultura, 2009, 31, 112-118.

Wagner Júnior, A.; Alexandre, R.S.; Negreiro, J.R.; Pimentel, L.D.; Costa E Silva, J. O.; Bruckner, C.H. Influência do substrato na germinação e desenvolvimento inicial de plantas de maracujazeiro amarelo (Passiflora edulis Sims f. flavicarpa Deg). Ciência e Agrotecnologia, 2006, 30, 643-647.

Zaccheo, P.V.C.; Aguiar, R.S.; Stenzel, N.M.C.; Neves, C.S.V.J. Tamanho de recipientes e tempo de formação de mudas no desenvolvimento e produção de maracujazeiro-amarelo. Revista Brasileira de Fruticultura, 2013, 35, 603-607. 